\title{
Suggestion on Annual Refund Ratio of Defect Repairing Deposit in Apartment Building through Defect Lawsuit Case Study
}

\author{
Deokseok Seo and Junmo Park
}

\begin{abstract}
The defect lawsuits over the apartment have not stopped in Korea. Especially because the legal ground on defect repair deposit and term of warranty liability is poorly provided, the dispute is heating up. Even if whopping 40 years have passed since the enactment of defect repair deposit Act, it has maintained its initial contents randomly enacted. This study performed the case study on defect lawsuit in order to consider the problem on annual refund regulation of defect repair deposit, to provide its ground. We calculated the construction type-specific defect repair cost, and the annual defect repair cost through case study. As a result, Reinforced Concrete Construction and Finishing Works showed high percentage in the aspect of the construction type-specific defect repair cost. The 10th year and the second year defect showed highest while the defects in the 3 4th showed relatively low proportion in the aspect of annual defect repair cost. Meanwhile the comparison between case data and the regulation of housing Act showed more actual defect repair cost was required in the 1-2 year and the 10th year than the regulation of housing Act while very little defect repair cost was actually required in the 3-5th year than regulated rate. When taking all these facts into account, as the defect repair deposit is the reserved money to prepare the case in which defect repair is not available, it is judged that it is desirable to increase and guarantee the 1-2 year and the 10th year by partially reducing the deposit of the 3-5 year with allowance where defect repair cost is less required. Based on this, we suggested new refund ratio of defect repair deposit which is composed of $15 \%$ for the first year, $35 \%$ for the second year, $10 \%$ for the $3-4$ th year and $40 \%$ for the 5-10th year.
\end{abstract}

Index Terms-Annual Refund Ratio, Defect Repairing Deposit, Defect Repairing Cost, Term of Warranty Liability, Defect Lawsuit, Apartment Building

\section{INTRODUCTION}

\section{A. Background}

Korea's universalized housing form is mostly composed of apartment housing, especially apartment. Korea's apartment has enjoyed the great popularity because they are more favorable than existing housing in various aspects which include housing convenience, safety and maintenance costs of residence. Therefore many of Koreans live in apartment now or hope to live in apartment. [1].

Manuscript received December 9, 2016.

Deokseok Seo, School of Architecture, Halla University, Wonju-si, Gangwon, 26404, Korea

Junmo Park, Gyeongsan Engineering, Seocho-gu, Seoul, 06646, Korea
The lawsuits over the defect of such apartments have become social problems in Korea. The issues of defect lawsuit are roughly divided into two. One is legal issue which includes responsibility bearing, liability period while the other is the technological issue which includes the definition of defect, repairing method and repairing cost [2].

Among various legal issues on defect lawsuit, defect repairing deposit is the reserved money to prepare the case in which construction company and business entity can't perform defect repair. But lawsuit brokers have estimated the damages based on defect repairing deposit in actual situation when they plan defect lawsuits [3].

Even if whopping 40 years have passed since the enactment of defect repairing deposit Act, it has maintained its initial contents randomly enacted. Moreover, the related legal ground has not suggested at all despite of many legal revisions. The ground systems which have been issued among defect repairing deposit Act, can be roughly divided into the deposit calculation method and refund of deposit when the defects liability period is terminated over the individual work for relevant year. When calculating defect repairing deposit, total construction cost and relevant ratio are the important matters. We have already investigated the problems through precedent study, suggested the proper ratio through case study [3]. Also the propriety of ratio was evaluated by related specialist [4]. On the contrary, the discussion on the refund of defect repairing deposit has scarcely been performed. Therefore the review on the propriety of annual refund ratio regulated by current law is required.

\section{B. Purpose}

This study conducted the review on the annual refund ratio of defect repairing deposit. The problem was drawn through the review of enactment ground of current regulation. And we performed the case analysis on the propriety of refund ratio which is annually regulated. We newly suggested the annual refund ratio of defect repairing deposit based on the result drawn from case analysis.

\section{Scope and Method}

The common housing of this study generally means apartment. Korea has regulated the common housing with five stories or more as apartment. For defect lawsuit, we targeted the group lawsuits jointly participated by many residents. Also the common housing includes the lot-solid apartment and leased apartment but we targeted the lot-solid apartment. Especially the time standard of defect lawsuit can be roughly divided into 
the third year and the 10th year. We targeted the third year of defect lawsuit cases. We divided the defect repair cost determined from lawsuit case by each construction and by defect liability period covering the first year to the 10th year and expressed in ratio. And we compared this ratio with the one regulated by housing Act [5].

\section{LITERATURE REVIEW}

\section{A. Refund Ratio of Defect Repairing Deposit}

The defect repairing deposit system for apartment in Korea is related to the enactment of Housing Construction Promotion Act in 1972 in order to promote housing construction in the industrialized society [6]. The regulation on annual refund ratio of defect repairing deposit was started with the enactment of Decree on the Management of Apartment Houses in 1979 [7]. $100 \%$ throughout 2 years was regulated in this time. Afterward, the regulation on refund ratio of defect repairing deposit specified the refund ratio allocated in two-year or one-year increments.

But no grounds or purposes were revealed for such a regulation. When Decree on the Management of Apartment Houses [7] was revised in 1981, it was revised to $20 \%$ for $1 \sim 2$ year, $20 \%$ for $5 \sim 10$ years(Table I). When Korea was at the height of industrialization in the 1970 1980s, Korean society lacked not only physical Infrastructure but also many social bases including cultural aspect, it was in the turbulent era of change.

Therefore the poor provisions of many social systems were inevitable, it is not uncommon to understand that the provisions on defect repair deposits were incomplete. But even after 1990s when Korean society has established itself and achieved the economic advancement, the effort for the completion of social system has not been provided. As a supporting evidence, it can be proved if the change history of related rules are researched in the 1990s. When Decree on the Management of Apartment Houses [7] was changed in 1998, the refund ratio of defect repair deposit was changed to $20 \%$ for the first year, $20 \%$ for the second year, $30 \%$ for the third year, $15 \%$ for the fifth year and $15 \%$ for the tenth year. But this also has no ground for revision as before. Afterward during the revision of Enforcement Decree of the Housing Act [5] in 2007, it was changed to $10 \%$ for the first year, $25 \%$ for the second year, $20 \%$ for the third year, $15 \%$ for the fourth year, $15 \%$ for the fifth year and $15 \%$ for the tenth year. No ground was revealed, either, it was revised unilaterally without any social agreement. Recently the related rules were changed to Apartment Buildings Management Act [8] in 2016. The refund ratio was also revised to $15 \%$ for the second year, $40 \%$ for the third year, $25 \%$ for the fifth year and $20 \%$ for the tenth year, no reason for revision was revealed as before.

When taking above facts into account, no grounds or purposes were revealed to explain the refund ratio of defect repairing deposit, any ground data was not suggested. Considering the status and importance that defect repair deposit has for defect lawsuit, it was proved that the related system doesn't correspond such a significance.
TABLE I: CHANGED HISTORY OF ANNUAL REFUND RATIO

\begin{tabular}{|c|c|c|c|c|c|c|c|c|}
\hline \multirow[t]{2}{*}{ No } & \multirow{2}{*}{$\begin{array}{c}\text { Date of } \\
\text { Establish } \\
\text { ment or } \\
\text { Revision }\end{array}$} & \multirow[t]{2}{*}{ Law } & \multicolumn{6}{|c|}{$\begin{array}{l}\text { Annual Refund Ratio of } \\
\text { Defect Repairing Deposit } \\
(\%)\end{array}$} \\
\hline & & & 1 & 2 & 3 & 4 & 5 & 10 \\
\hline 1 & 1979 & $\begin{array}{l}\text { Regulations } \\
\text { on the } \\
\text { Management } \\
\text { of Apartment } \\
\text { Buildings }\end{array}$ & \multicolumn{2}{|c|}{100} & - & - & - & - \\
\hline 2 & 1981 & $\begin{array}{l}\text { Decree on the } \\
\text { Management }\end{array}$ & \multicolumn{2}{|c|}{80} & - & - & \multicolumn{2}{|c|}{20} \\
\hline 3 & 1998 & $\begin{array}{l}\text { of Apartment } \\
\text { Houses }\end{array}$ & 20 & 20 & 30 & - & 15 & 15 \\
\hline 4 & 2007 & Housing Law & 10 & 25 & 20 & 15 & 15 & 15 \\
\hline 5 & 2016 & $\begin{array}{l}\text { Apartment } \\
\text { House } \\
\text { Management } \\
\text { Law }\end{array}$ & - & 15 & 40 & - & 25 & 20 \\
\hline
\end{tabular}

\section{B. Definition on Defect Repairing Deposit}

It is required to designate the defect repairing deposit first of all in order to provide the ground for annual refund ratio of defect repairing deposit. But the current rule poorly provided the defect repair deposit in the actual situation. Accordingly, the precedent study suggested the defect repair cost which is the most suitable concept for defect repair deposit, the sentenced money shall be the defect repair cost in defect lawsuit.

If the contents of precedent study is briefly reviewed, they are as follows. The defect repair deposit prepared the case when business entity with the responsibility of defect repair can't provide the defect repair. When the business entity goes bankrupt or can't provide the defect repair, the rule regulates so that the residents can do defect repairing with defect repair deposit. Even if the defect repair deposit has limited in use, we can know that it was set for defect repair. So it is considered the calculation of defect repair deposit should be linked with defect repair cost [3].

If it is researched in the aspect of defect lawsuit, the defect repair cost means the damages paid to plaintiff as a result of judgement

The concept of defect repairing cost means the total cost which has been used for the actual defect repair. We can consider such a defect repairing cost by dividing into following 3 kinds.

First, there is a defect occurred before the apartment completion, at the stage of move in.

Second, there is the cost for defects occur due to the use of residents, the poor maintenance of managing entity and natural damage when several years have passed after move at the stage of use. Because the defect liability period remains in these two case, it is hard to accurately figure out the cost as the defect repair is provided even if the separate cost is not provided. Finally, above two cases have the cost paid as damages when the partitioned owner not satisfied with the first defect repair files a lawsuit. Such a cost is evaluated by professional appraiser, it is relatively easier to figure out defect repair cost. When taking above facts into account, this study assumed the sentenced money as the criteria for defect repair deposit. 


\section{CASE STUDY}

\section{A. Outline}

This study calculated the defect repair cost through case study of defect lawsuit, totaled the defect repair cost by construction types and annual bases. And the suitability of Housing Act was reviewed by comparing this with the annual refund ratio of Housing Act.

Total 100 defect lawsuit cases were collected for case analysis. After reviewing the basics of each data, it was proved that there mixed the cases of lot-solid apartment and leased apartment The cases of leased apartment were excluded because its too small number is not suitable for statistical analysis. Moreover, the defect lawsuits are divided into the 3th year lawsuit and the 10th year lawsuit. In case of the 3th year lawsuit, it was filed for all types of construction involved in apartment construction.

On the contrary, the 10th year lawsuit, reinforced concrete works take up the majority, other construction is very few. Therefore it is estimated this study might have the different annual analysis result, because the result value biased to specific construction might be obtained, only the 3 th year lawsuit was analyzed. When taking above facts into account, 48 cases were analyzed finally.

In order to calculate annual defect repair cost, construction type-specific defect repair cost should be calculated. Also, repeated calculation per each year should be performed in order to calculate annual defect repair cost as detailed construction types have different defect liability period within the same construction type. We referred Enforcement Decree of the Housing Act to research the defect liability period by construction type. The related contents were omitted because of lack of space, please refer the reference [9].

\section{B. Defect Repairing Cost by Work Type}

The ratio of defect repair cost was divided by 18 construction types of Housing Act as following Figure 1. The highest ratio was $37.36 \%$ of reinforced concrete work which is followed by $25.66 \%$ of finishing work, $8.97 \%$ of landscape work. Other than these, it was proved that much defect repair cost was required for roof and waterproofing works, water supply, drainage and sanitation facilities construction, window construction and other construction.

On the contrary, outdoor water supply and sanitary facilities construction, steel structure construction, masonry construction, woodworking, heating ventilation and air conditioning facilities construction, gas and fire fighting facilities construction, electricity and electric power facility construction, communication signal and disaster prevention equipment construction and intelligent home network construction, etc showed under $3 \%$ which is very low. It is judged that no defect occurred for foundation work had no defect repair cost.

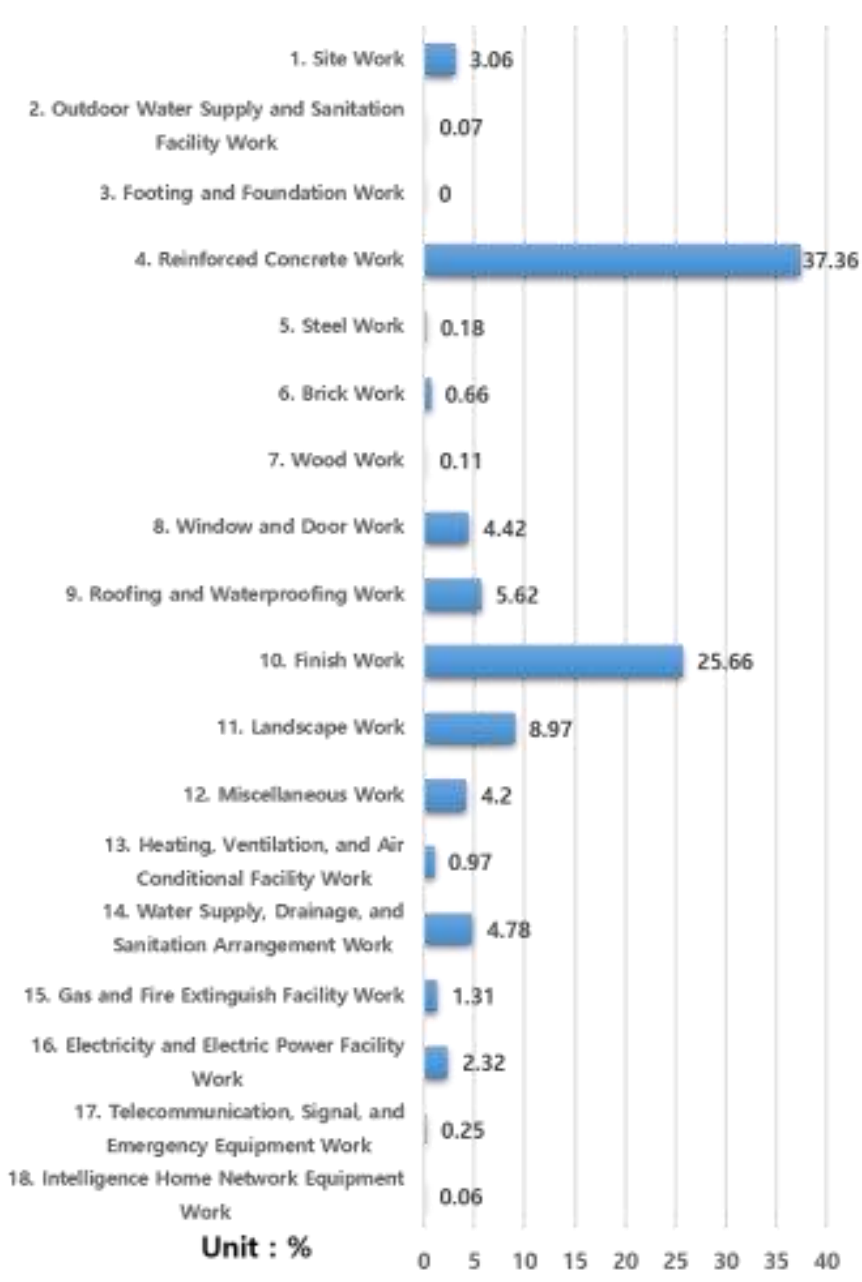

Fig. 1. Whole status of defect repairing cost by work type

\section{Annual Defect Repairing Cost}

Following figure calculated and organized the above researched construction type-specific defect repair cost by annual basis (Figure 2). The defect of the first year takes up 16\% of total defect, the second year defect takes up 37\%, the third year defect $3 \%$, the fourth year defect $6 \%$ and the tenth year defect showed $38 \%$. It was shown that the fifth year had no defect. In the aspect of defect repair cost, the tenth year defect and the second year defect take up the majority while the 3-4th year defects were relatively very few.

Meanwhile, the reason why there exists no defect in the fifth year is as follows. Originally, some of reinforced concrete work should have included to the 4-5th year defect, this study included all of them to the tenth year defect considering that the defect liability period of reinforced concrete work is 10 year. According to Housing Act, the defect of reinforced concrete work is 4 years while it is generally 5 years under Collective Building Act, it is 10 years for the structural strength [10]. The standards of similar Act are mixed, it is considered the defect liability of reinforced concrete work is 10 years in accordance with the judgment of Supreme Court. Therefore we declare that it was calculated that there were no defects in the fifth year because this study followed such a standard. 


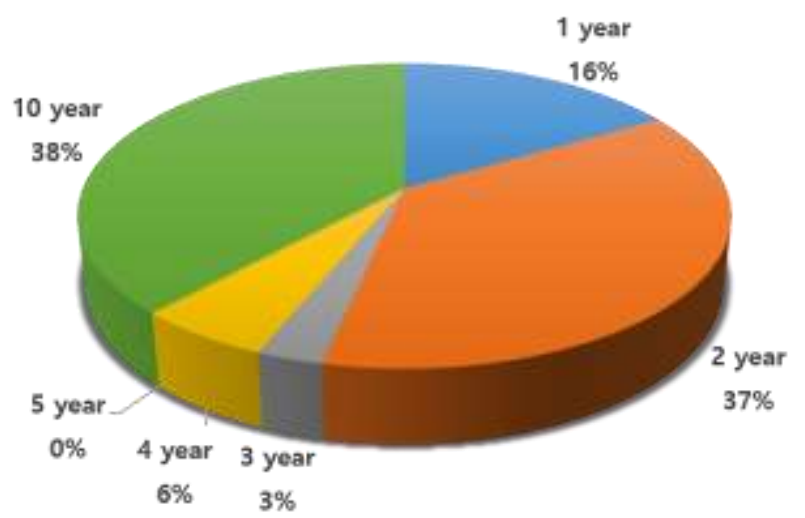

Fig. 2. Status of Annual defect repairing cost

\section{Comparison}

The comparison of performance data drawn through case analysis and annual refund ratio of defect repair deposit regulated by Enforcement Decree of the Housing Act is as follows (Figure 3). As above table 1, the annual refund ratio of defect repair deposit under Housing Act shows $10 \%$ for the first year, $25 \%$ for the second year, $20 \%$ for the third year, $15 \%$ for the fourth year, $15 \%$ for the fifth year and $15 \%$ for the tenth year. The annual ratio of defect repair cost drawn through case analysis shows $16 \%$ for the first year, $37 \%$ for the second year, $3 \%$ for the third year, $6 \%$ for the fourth year, $0 \%$ for the fifth year and $38 \%$ for the tenth year.

When comparing this result, the defect repair cost actually required in the 1-2th year is higher than the ratio set by Housing Act. The excess ratio is $6.5 \%$ in the first year, $11.9 \%$ in the second year. It shows its unreasonable structure where the defect repair deposit in the 1 2th year is less than the actual defect repair cost. Therefore it is necessary to level up the refund ratio in the 1 2th year.

On the contrary we can see that the actual cost in the 3-4th year is ridiculously small than the cost set by Housing Act. While the cost in the third year was set $20 \%$, the actual cost is only $2.8 \%$ with $17.2 \%$ excess. The cost in the fourth year was set $15 \%$, but actual cost is only $5.7 \%$ with about three times excess.

As above mentioned, we can say the cost of the fifth year is meaningless setting if considering the speciality of reinforced concrete work, Last, the case of the tenth year, setting ratio is $15 \%$ but the actual defect ratio is whopping $38.1 \%$. As this case requires more than 2 times higher defect repair cost so it is necessary to level up the refund ratio as the case of 1-2th year.

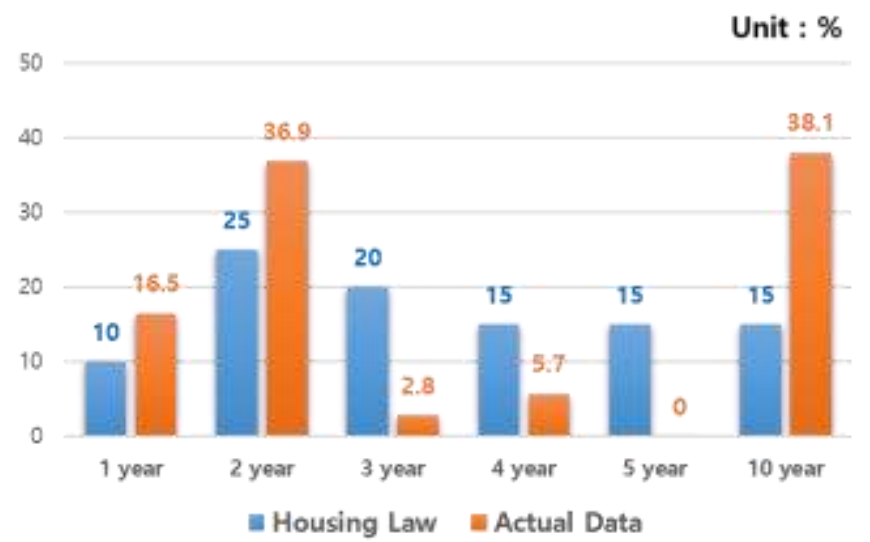

Fig. 3. Comparison of Refund Ratio in Housing Law and Actual Data

\section{E. Result and Implication}

The review result of annual refund ratio of defect repair deposit through defect lawsuit case analysis is as follows. First, the review of construction type specific defect repair cost showed that reinforced concrete construction, Finishing work and Landscape construction take up high percentage of defect repair cost. Also the annual review showed that the defects of the tenth year and the second year take up high percentage while the 3-4th year takes up relatively low percentage.

The comparison between actual performance data and the regulation of Housing Act showed that the case of the 1-2th year and the tenth year required more defect repair cost than the regulations. It means that the defect repair cost and the defect repair deposit should be allocated more in the relevant year. Because the defect repair deposit should prepare the none implement of defect repair, it should be intensively allocated for the 1-2th year and the tenth year when the defect repair is frequently performed. On the contrary, it was proved that the 3-5th year had relatively less actual defect and the defect repair deposit was set too generously.

Based on the result of this case analysis, it is judged that it is desirable to make adjustments in order to guarantee the 1-2th year and the tenth year when much defect repair cost is required by partially adjusting the deposit of the 3-5th year which has much allowance.

\section{F. Suggestion}

When taking above analyzed result into account, this study suggests the annual refund ratio of defect repair deposit as follows (Figure 4). We level up the defect repair deposit of the 1-2th year and the tenth year than existing ratio, level down the case of the 3-5th year. As a result, we suggest $15 \%$ for the first year, $35 \%$ for the second year, $10 \%$ for the $3-4$ th year and $40 \%$ for the 5-10th year. 


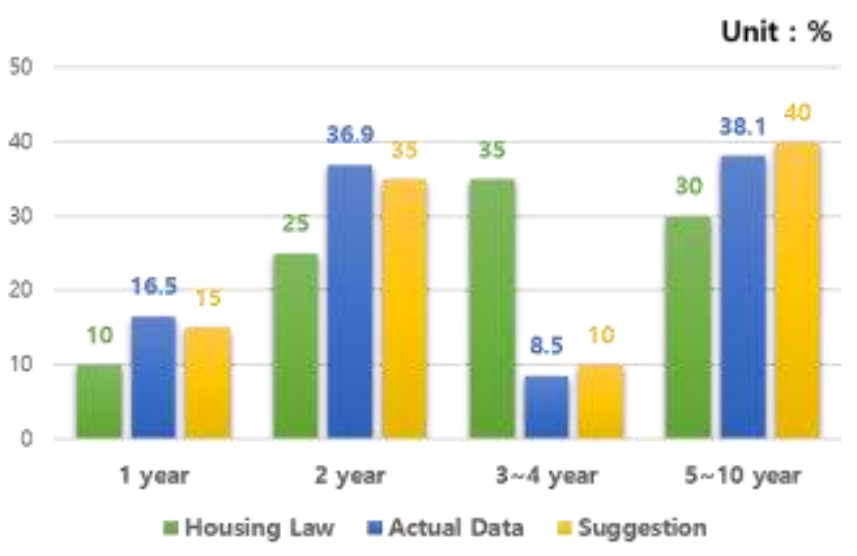

Fig. 4. Suggestion on Annual Refund Ratio

\section{CONCLUSION}

The defect lawsuits over the apartment have not stopped in Korea. Especially because the legal ground on defect repair deposit and term of warranty liability is poorly provided, the dispute is heating up.

Even if whopping 40 years have passed since the enactment of defect repairing deposit Act, it has maintained its initial contents randomly enacted. Moreover, the related legal ground has not suggested at all despite of many legal revisions. The ground system which has been issued among defect repairing deposit Act, can be roughly divided into the deposit calculation method and refund of deposit when the defects liability period is terminated over the individual work for relevant year.

This study performed the case study on defect lawsuit in order to consider the problem on annual return regulation of defect repair deposit, to provide its ground. We targeted 48 lot-solid apartment buildings in the third year to calculate the construction type specific defect repair cost, the annual defect repair cost was calculated by dividing them according to defect liability period per each construction. We summarized the result as follows. First it was found that the highest defect repair cost shows in the order of the reinforced concrete work, finishing work and landscape work. Second, it was significantly contrasted that the 10th year and the second year defect repair cost was the highest while the 3-4th year defect was relatively less. Third, the comparison between Housing Act and defect lawsuit case data showed that more actual defect repair cost of the 1-2th year and the tenth year is required than the ratio regulated by Housing Act. On the contrary it was shown the much less actual cost was used than the regulated ratio in the $3-5$ th year. When taking above into account, it is judged that it is desirable to make adjustments in order to guarantee the 1-2th year and the tenth year when much defect repair cost is required by partially adjusting the deposit of the 3-5th year with much allowance as the defect repair deposit should prepare the none implement of defect repair.

Base on this, we suggest new refund ratio of defect repair deposit which includes $15 \%$ for the first year, $35 \%$ for the second year, $10 \%$ for the $3-4$ th year and $40 \%$ for the 5-10th year.

In the future, the research for the suitability verification of suggested defect repair deposit will be promoted.

\section{REFERENCES}

[1] J. Park and D. Seo, "Basic Study on Influence Factors for Defect Repairing Cost of Apartment Building in Korea," presented at the 2016 International Conference on Applied Mathematics and Mechanics, Bangkok, Thailand, Oct 29-30, 2016.

[2] J. Park and D. Seo, (December 2014) Development of standard work process model for defect consulting on Korea apartment housing. International Journal of Applied Engineering Research. [Online]. 9(23). Pp.18167-18174. https://www.ripublication.com/Volume/ijaerv9n23.htm.

Available:

[3] J. Park and D. Seo, "Suggestion on Estimating Rate for Defect Repairing Deposit through Case Study of Defect Lawsuit in Korean Apartment Building," presented at the International Conference Nanotechnology, Environmental, and Civil Engineering, Bangkok, Thailand, Dec 25-26, 2016

[4] J. Park and D. Seo, "Comparative Review on Estimating Rate for Defect Repairing Deposit in Apartment Building through Survey with Experts." presented at the International Conference Nanotechnology, Environmental, and Civil Engineering, Bangkok, Thailand, Dec 25-26, 2016

[5] Housing Law

[6] Housing Construction Promotion Act

[7] Decree on the Management of Apartment Houses

[8] Apartment House Management Law

[9] National Law Information Center, Defect Scope for Defect Repairing Target and Term of Warranty Liability by Work Type in Apartment Building. Available: http://www.law.go.kr/lsBylInfoR.do?bylSeq=6441795\&lsiSeq=184332 \&efYd=20160701

[10] Act on Ownership and Management of Condominium Buildings

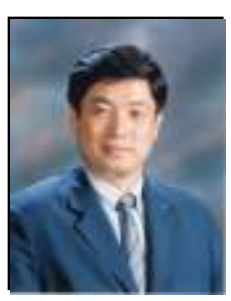

Deokseok Seo was born in Gongju, Korea in 1964. He currently lives in Wonju, Korea and is a professor of the College of Architecture at Halla University. He received bachelor's, master's, and doctoral degrees from Korea University in Korea. He also worked as a researcher at Korea Land \& Housing Corporation, the only professional public company in Korea's apartment houses. He is the first researcher who received a doctorate in research on defects in apartment housing in Korea. Until now, he has been conducting various researches with government support on defects in apartment houses. In 2016, he was also listed in the World Dictionary of Marquis Who's Who in the World. In addition, he received a commendation from the Minister of Education as an excellent researcher. He has done various researches with Dr. Junmo Park, and has written academic papers and thesis. Recently, with the support of the Korea Research Foundation, a specialized research institute under the Ministry of Education, Korea, he is conducting a study on the term of warranty liability in apartment buildings.

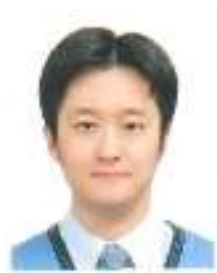

Junmo Park was born in 1980 in Seoul, South Korea. He currently lives and works for Gyeongsan Engineering in Seoul. He majored in Architectural Engineering at the Chungbuk National University in Korea, graduated in 2006 with a master's degree in 2008, and received his $\mathrm{Ph} . \mathrm{D}$ in 2012. Since 2005, he has been involved in various research and development projects commissioned by the Korean government and corporations and has lectured at many universities since 2010. Research on the defects of apartment buildings has been carried out with Professor Deokseok Seo, with support from Korean government over 5 projects since 2008. Currently, he is working with Professor Deokseok Seo on the term of warranty liability for apartment housing. 